\title{
PENGUJIAN HUBUNGAN STRUKTURAL CITRA DESTINASI WISATA, KEPUASAN WISATAWAN DAN LOYALITAS WISATAWAN: KASUS PULAU LOMBOK
}

\author{
Dwi Putra Buana Sakti ${ }^{1}$, Siti Nurmayanti ${ }^{2}$ Hermanto $^{3}$ \\ ${ }^{1}$ Fakultas Ekonomi dan Bisnis, Universitas Mataram, dwiputrabs39@gmail.com \\ ${ }^{2}$ Fakultas Ekonomi dn Bisnis, Universitas Mataram, mayaramli24@gmail.com \\ ${ }^{3}$ Fakultas Ekonomi dn Bisnis, Universitas Mataram hermanto2307@gmail.com
}

\begin{abstract}
ABSTRAK
Petumbuhan potensi wisatawan muslim yang besar selama ini belum digarap sepenuhnya oleh pelaku pariwisata Indonesia. Peluang ini telah diantisipasi oleh beberapa negara tetangga dengan mengembangkan wisata halal secara serius. Oleh karena itu, diperlukan upaya untuk mengembangkan destinasi wisata halal disamping destinasi wisata umum yang telah ada untuk menarikkunjungan wisatawan nusantara maupun wisatawan mancanegara. Potensi wisatawanmuslim mancanegara yang belum dioptimalkan merupakan pekerjaan rumah yang perlu diselesaikan bersama oleh stakeholders pariwisata.

Penelitian ini ditujukan untuk menguji hubungan struktural antara citra Pulau Lombok sebagai destinasi wisata halal, kepuasan wisatawan dan loyalitas wisatawan. Penelitian dilakukan di Pulau Lombok yang telah mendapatkan penghargaan sebagai destinasi wisata halal pada tahun 2015.Pengumpulan data dilakukan melalui penyebaran kuesioner terhadap 150 orang wisatawan yang berkunjung ke Pulau Lombok selama kurun waktu penelitian dilakukan. Temuan penelitian menunjukkan citra Pulau Lombok sebagai destinasi wisata halal memengaruhi kepuasan dan loyalitas wisatawan yang mengunjunginya.

Kata kunci: citra destinasi wisata, kepuasan wistawan, loyalitas wisatawan, Pulau Lombok, Structural Equation Modeling (SEM)
\end{abstract}

\section{ABSTRACT}

The growing potential of large Moslem tourists has not been fully worked out by Indonesian tourism actors. This opportunity has been anticipated by several neighboring countries by developing seriously halal tourism. Therefore, efforts are needed to develop halal tourism destination in addition to existing public tourism destinations to attract tourists and foreign tourists. The potential of foreign tourists who have not been optimized is a homework that needs to be solved together by tourism stakeholders.

This research is intended to examine the structural relationship between the image of Lombok Island as a halal tourist destination, tourist satisfaction and tourist loyalty. The study was conducted in Lombok Island which has been awarded as a halal tourism destination in 2015. Data collection was done through the spreading of questionnaires to 150 tourists who visited the island of Lombok during the period of research conducted. The research findings show the image of Lombok Island as a halal tourism destination affecting the satisfaction and loyalty of tourists who visit it.

Keywords: tourist destination image, tourist satisfaction, tourist loyalty, Lombok Island, Structural Equation Modeling (SEM) 


\section{PENDAHULUAN}

Pulau Lombok yang telah mendapatkan penghargaan sebagai destinasi wisata halaldalam pengembangannya memerlukansejumlah tolok ukur, salah satunya bersumber dari wisatawan.Penilaian wisatawan mengenai destinasi wisata dipandang penting karena mereka adalah konsumen yang menikmati jasa (layanan) yang disediakan.Wisatawan memberikan penilaian terhadap suatu destinasiwisata melalui kepercayaan dan persepsi mereka,yang selanjutnya disebut sebagai citra destinasi.

Citra destinasi (destination image) berkaitan dengan apa saja yang dipersepsikan seseorang mengenai destinasiwisata dan apa yang dirasakanselama mengunjunginya. Citra destinasi wisata memiliki peran penting untuk keberhasilan suatudestinasiwisata karena memberikan efek multidimensi bagi wisatawan maupun masyarakat lokal. Persepsi wisatawan terhadap citradestinasiwisatamemengaruhi kepuasan dan niat mengunjunginya diwaktu yang akandatang. Tentu saja keputusan ini tergantung pada kemampuan destinasi wisata memberikan pengalaman positif yang tidak terlupakan yang diperoleh selamaberwisata.Beerli \&Martin (2004)telah mengkonfirmasi bahwa hasilpenelitian empiris mendukung adanya pengaruh positif citra destinasi wisata terhadap kepuasan dan perilaku wisatawan.Demikian pula, Bigne et al.,(2001)melaporkan temuannya bahwacitra destinasi berpengaruh positifterhadap kepuasaan dan perilaku wisatawan.

Faktor lainyang perlu diperhatikan agar pengembangandestinasi wisata sesuai dengan kebutuhan wisatawan adalah memperhatikan hal-hal yang berpengaruh terhadap kepuasan mereka. Kepuasan wisatawan dapat dipertimbangkanmelalui penilaian keseluruhan wisatawan. Penilaian tersebut berkaitan dengan kualitas layanan yang tersedia di suatu destinasi wisata.Pengembangan destinasi wisata yang tepat, diharapkan mampu memberi kepuasan kepada wisatawan sehingga mereka berencana untuk berkunjung kembali atau merekomendasikan destinasi wisata tersebut kepada orang lain. Perilaku wisatawan paska kunjungannya ke destinasi wisata berkaitan dengan loyalitas mereka.

Citra destinasiwisata (destination image) dapat memengaruhi kepuasan wisatawan (tourist satisfaction) serta loyalitas wisatawan (tourist loyalty). Coban (2012) membuktikan dalam penelitiannya bahwa citra destinasi wisata yang positifmampu meningkatkan kepuasan wisatawan. Selanjutnya, Coban (2012) juga menjelaskan bahwa wisatawan yang menilai positifcitra suatu destinasi wisatacenderung bersedia berkunjung kembali dan merekomendasikan destinasiitu ke orang lain. Penelitian yang dilakukan Coban (2012) juga menunjukkan bahwa kepuasan memiliki pengaruh yang positifterhadap perilaku setelah berkunjung.

Penelitian ini penting dilakukan karena dengan mengetahui pandangan wisatawan mengenai citra Pulau Lombok sebagai destinasi wisata halal diharapkanpengembangan pariwisata Pulau Lombok akan selaras dengan kebutuhan wisatawan. Sehingga mereka memperoleh kepuasan ketika berkunjung dan di kesempatan berikutnya mengulangi kunjunganatau setidaknya merekomendasikan Pulau Lombok sebagai destinasi wisata yang pantas dikunjungi ke orang lain.

\section{Perumusan Masalah}

Berdasarkan paparan tersebut, rumusan masalah penelitian ini ada tiga, yaitu:

1. Apakah citra Pulau Lombok sebagai destinasi wisata halal berpengaruh signifikan terhadapkepuasan wisatawan yang mengunjung Pulau Lombok?

2. Apakah citra Pulau Lombok sebagaidestinasi wisata halal berpengaruh signifikan terhadaployalitas wisatawan yang mengunjungi Pulau Lombok? 
3. Apakah kepuasan wisatawanberpengaruh terhadap loyalitas wisatawan yang mengunjungi Pulau Lombok?

\section{TINJAUAN TEORITIS DAN PENGEMBANGAN HIPOTESIS}

\section{Citra Destinasi Wisata}

Citra (image) destinasi wisata menurut Pitana danDiarta (2009) adalah kepercayaan yang ada dalam diri wisatawan mengenai produk atau pelayanan yang dibeli atau yang akandibeli. Terbentuknya citra destinasi wisata tidak saja berasal dari pengalaman atau fakta, namun dapat juga dibentuk sebagaifaktor pendorong yang kuat untukmelakukan perjalanan wisata ke suatu destinasiwisata tertentu. Wisatawan bisa saja memiliki penilaianberbeda-beda antara satu dengan yang lain mengenai citra destinasi wisata yang sama. Terkait dengan unsur-unsur yang membentuk citra destinasi wisata, Coban (2012) menyatakan bahwa citra destinasiterdiri dari hasil penilaian rasional atau citrakognitif (cognitive image) dan penilaian emosionalatau citra afektif (affective image) dari destinasi itusendiri.

Salah satu faktor mendasar yang mendukung keberhasilan pengembangan destinasi wisata adalah citra positif mengenainya.Citra destinasi wisata memberi efek multi-dimensi terhadap masyarakat lokal maupun wisatawan itu sendiri.Mengenai hal ini, Beerli \& Martin (2004) mengemukakan bahwa "persepsi terhadap citra destinasi wisatadapat memengaruhi kepuasan dan niat untuk mengunjunginya di waktu yang akandatang, yang tentu saja tergantung pada kemampuan destinasi wisata itu untuk memberikan pengalaman positif yang tak terlupakan yang diperoleh selamaberwisata".Peneliti lain seperti Bigne et al., (2000) juga menemukan bahwacitra destinasi wisata berpengaruh positif terhadap kepuasan dan perilaku wisatawan, dengan demikian hipotesis pertama dalam penelitian ini adalah:

H1: Citra Pulau Lombok sebagai destinasi wisata halal berpengaruh signifikan terhadap kepuasan wisatawan yang berkunjung.

\section{Kepuasan Wisatawan}

Pada dasarnyakonsep kepuasan bukan semata-mata mengenai laba, namunjuga untuk memuaskan konsumen. Sebagaimana yang dikemukakan Kotler dan Keller (2008) bahwa kepuasan yang dirasakan konsumen adalah derajat perasaannya setelah membandingkan kinerja yang dirasakan dengan harapan.Mereka yang merasa tidak puas terhadap pelayanan yang diperoleh cenderung membawa akibat negatif, begitu pula sebaliknya.

Konsumen yang merasa puas terhadap layanan yang diterima, bisa mendatangkan beberapa keuntungan sebagaimana disebutkan Tjiptono $(2007 ; 24)$ sebagai berikut, a. hubungan antara konsumen dan perusahaan menjadi harmonis, b. memberikan dasar yang baik bagi pembelian ulang, c. terciptanya loyalitas konsumen, d. membentuk rekomendasi dari mulut ke mulut. Konsumen yang puas akan merek suatu tempat yang digunakannya akanmemberitahukan kelebihan-kelebihan merek tersebut kepada orang lain, danselanjutnya konsumen akan merekomendasikannya kepada orang lain.

Silverman (2001) menyatakan bahwa testimoni dan rekomendasiyang diberikan pelanggan dapat menjadi sarana promosi yang efektif dalammembujuk konsumen lain untuk membeli produk. Hal inimerupakan salah satu strategi komunikasi pemasaran mendasar yang sering disebutdengan Word of Mouth. Besarnya frekuensi orang membicarakan merek suatu tempatkepada orang yang tepat dengan cara yang benar merupakan hal yang paling penting. Hal ini selaras dengan pendapat Dye (2000) yang 
menyatakan Word of Mouth lebih dipercaya dibandingkan dengasales person, serta dapatmenjangkau konsumen lebih cepat daripada iklan maupun direct mail, karena word of mouthmampu memberikan rekomendasi.

Harapan konsumen umumnya disandarkan pada pengalamanmasa lalu, testimoni kerabat, teman serta janji dan informasi yang berasal dari pemasar ataupun pesaingnya. Kepuasan konsumen yang terpenuhi, memberi manfaat kepada produsenpenyedia produk atau jasa karena pembeli akan melakukan pembelian ulang yang pada akhirnya mencptakan loyalitas terhadap jasa pelayanan yangditerima. Umumnya, konsumen yang merasa puas akan merekomendasikan dari mulut ke mulut kepada temansekitarnya untuk menggunakan produk atau jasa tersebut (Bigne et al,2005: Baker danCrompton, 2000), dengan demikian hipotesis kedua dalam penelitian ini adalah:

H2: Kepuasaan wisatawan berpengaruh signifikan terhadap loyalitas wisatawan yang berkunjung ke Pulau Lombok.

\section{Loyalitas Wisatawan}

Loyalitas menurut Lovelock et al., (2010) merupakan kesediaan pelanggan untuk selalu membeli produk suatu perusahaan dalam jangka waktu yang panjang, bahkan menggunakannya secara ekslusif, serta merekomendasikan produk-produk tersebut pada orang lain. Dalam literature pariwisata, kesediaanmenggunakan produk perusahaan dalam jangka panjang dikaitkan dengan kesediaan wisatawan untuk berkunjung kembali ke suatu destinasi di masa mendatang.

Artuğer et al. (2013) mengemukakan dua faktor penentu loyalitas terhadap destinasi wisata sebagai berikut: pertama, Intention to revisit the destination, yang berarti bahwa wisatawan yang loyalakan berkunjung kembali pada kesempatan berikutnya. Kedua, saypositive things about the destination and recommendations to others, bahwa wisatawan yang loyalakan menyampaikanhal-hal positif mengenai destinasi wisata itu, bahkan merekomendasikannya kepada orang lain. Perilaku paska kunjungan dan seberapa utuh wisatawan mengevaluasi kunjungannya akan mempengaruhi minat melakukan kunjungan kembali serta kesediaan mereka untuk merekomendasikan kepada orang lain (Bigne, Sanchez dan Sanz 2005) maka hipotesis ketiga dalam penelitian ini adalah:

H3: Citra Pulau Lombok sebagai destinasi wisata halal berpengaruh signifikan terhadap loyalitas wisatawan yang berkunjung ke Pulau Lombok.

\section{METODE PENELITIAN}

Penelitian ini merupakan penelitian kausalitas yang ditujukan untuk menguji pengaruh citra Pulau Lombok sebagai destinasi wisata halal, kepuasan wisatawan dan loyalitas wisatawan yang mengunjunginya. Populasi target penelitian adalah wisatawan domestik berusia diatas 17 tahun yang sedang berkunjung ke Pulau Lombok selama penelitian berlangsung. Pengumpulan data melalui survei dilakukan selama 4 bulan dalam kurun waktu Juli sampai dengan Oktober 2017.Jumlah sampel yang ditetapkan sejumlah 150 orang wisatawan. Desain sampel yang digunakan adalah desain non-probality sampling, bercirikan setiap anggota populasi tidak memiliki kesempatan yang sama untuk dipilih sebagai sampel. Teknik pengambilan sampel yang dipakai adalah purposive sampling.Teknik purposive sampling berarti anggota populasi dapat ditetapkan sebagai sampel sepanjang memenuhi karakteristik anggota populasi dan sesuai dengan tujuan penelitian.Hipotesis yang diajukan diuji dengan analisis jalur (path analysis).Analisis jalur merupakan perluasan dari analisis regresi linear berganda, atau analisis jalur adalah penggunaan analisis regresi untuk menaksir hubungan kausalitas antar variabel (model 
causal) yang telah ditetapkan sebelumnya berdasarkan teori (Ghozali, 2012). Selanjutnya menurut Ghozali (2012), untuk melakukan pengujian hipotesis mediasi dapat dilakukan dengan prosedur yang dikembangkan oleh Sobel (1982) dan dikenal dengan uji Sobel (Sobel test), dengan cara menguji kekuatan pengaruh tidak langsung variabel independen ke variabel dependen melalui variable mediasi.

\section{HASIL DAN PEMBAHASAN}

Wisatawan dari Propinsi Jawa Timur merupakan responden yang paling banyak mengunjungi Pulau Lombok. Tingginya kunjungan wisatawan asal propinsi Jawa Timur ke Pulau Lombok disebabkan karena aksesibilitas menuju Pulau Lombok dari daerah Jawa Timur relatif mudah.Hanya dibutuhkan waktu 55 menit penerbangan untuk tiba di Pulau Lombok.Moda transportasi pesawat terbang masih menjadi pilihan utama bagi responden yang berkunjung ke Pulau Lombok.Pilihan berikutnya adalah menggunakan kapal penyeberangan yang melayani rute Padang Bai - Lembar.Teman sebagai sumber informasi yang bisa dipercaya merupakan pilihan yang dominan bagi responden yangg berkunjung ke Pulau Lombok untuk dijadikan rujukan.Sumber informasi lainnya yang tidak kalah penting adalah rujukan yang diakses melalui internet.Demikian pula, informasi yang diberikan oleh saudara yang pernah berkunjung ke Pulau Lombok menjadi sumber informasi yang bisa dipilih responden untuk memutuskan ke Pulau Lombok.Selama berada di Pulau Lombok, sebagian besar responden (87\%) menghabiskan waktunya berkisar antara dua hingga sepuluh hari. Umumnya, mereka memanfaatkan waktu tersebut untuk mengunjungi obyek wisata yang telah mereka dengar sebelumnya diantaranya obyek wisata Pantai Senggigi, Gili Terawangan, Pantai Kuta, Desa Adat Sade dan beberapa obyek wisata lainnya yang menarik.

Sesuai dengan tujuan penelitian untuk menguji hubungan structural yang dihipotesiskan diantara variable yang ada, digunakan model persamaan struktural dengan bantuan software AMOS 23. Skor faktor digunakan sebagai indikator item tunggal untuk melakukan analisis jalur melalui penerapan metode pendugaan kemungkinan maksimum (MLE) sesuai pedoman yang dianjurkan Joreskog dan Sorbom (1982). Analisis terperinci hasil dan pengukuran kecocokan model dirangkum pada Tabel 4.1 berikut.

Tabel 1. Hasil Uji Analisis Jalur

\begin{tabular}{|c|c|c|c|c|}
\hline $\begin{array}{l}\text { Variabel } \\
\text { prediktor }\end{array}$ & $\begin{array}{l}\text { Variabel } \\
\text { kriteria }\end{array}$ & $\mathrm{CR}$ & $\begin{array}{l}\text { Koefisien } \\
\text { baku }\end{array}$ & $R^{2}$ \\
\hline $\begin{array}{l}\text { Citra Destinasi } \\
\text { Wisata }\end{array}$ & $\begin{array}{l}\text { Kepuasan } \\
\text { Wisatawan }\end{array}$ & 3.204 & $0,837 * *$ & \multirow{3}{*}{0,720} \\
\hline $\begin{array}{l}\text { Citra Destinasi } \\
\text { Wisata }\end{array}$ & $\begin{array}{l}\text { Loyalitas } \\
\text { Wisatawan }\end{array}$ & 3.038 & $0,260 * *$ & \\
\hline $\begin{array}{l}\text { Kepuasan } \\
\text { Wisatawan }\end{array}$ & $\begin{array}{l}\text { Loyalitas } \\
\text { Wisatawan }\end{array}$ & 2.800 & $0,652 * *$ & \\
\hline Statistik & & & Dianjurkan & Diperoleh \\
\hline \multicolumn{3}{|c|}{ Signifikansi kuadrat chi } & $\geq 0,05$ & 6,228 \\
\hline \multicolumn{3}{|c|}{ Indeks kecocokan suai (GFI) } & $\geq 0,90$ & 0,997 \\
\hline \multicolumn{3}{|c|}{$\begin{array}{l}\text { Indeks kecocokan suai yang disesuaikan } \\
\text { (AGFI) }\end{array}$} & $\geq 0,80$ & 0,970 \\
\hline \multicolumn{3}{|c|}{ Indeks kecocokan komparatif(CFI) } & $\geq 0,90$ & 0,998 \\
\hline \multicolumn{3}{|c|}{ Indeks kecocokan bernorma (NFI) } & $\geq 0,90$ & 0,997 \\
\hline \multicolumn{3}{|c|}{ Residual akar purata kuadrat (RMSEA) } & $\geq 0,08$ & 0,008 \\
\hline
\end{tabular}


Merujuk pada Tabel 1 di atas, angka indeks yang ditampilkan menegaskan bahwa keseluruhan kecocokan model tersebut dengan data cukup baik, sehinggamodel evaluasi pada penelitian ini dapat diterima sebagai model akhir untuk dilakukan interpretasi dan uji hipotesis sebagai berikut:

1. koefisien regresi yang dibakukan sebesar 0.837 pada hubungan citra Pulau Lombok sebagai destinasi halal terhadap kepuasan wisatawan dengan C.R. sebesar 3.204 dan $p_{\text {value }}=0,006$ (lebih kecil dari 0,05) membuktikan adanya pengaruh positif dan signifikan diantara keduanya. Dengan demikian diperoleh cukup bukti bahwa hipotesis $\mathrm{H}_{1}$ yang menyatakan citra Pulau Lombok sebagai destinasi wisata halal memiliki pengaruh positif terhadap kepuasan wisatawan muslim yang berkunjung ke Pulau Lombok dapat diterima.

2. koefisien regresi yang dibakukan sebesar 0,260 pada hubungan citra Pulau Lombok sebagai destinasi halal terhadap loyalitas wisatawan dengan C.R. sebesar 3.038 dan $p_{\text {value }}=0,023$ (lebih kecil dari 0,05 ) membuktikan adanya pengaruh positif dan signifikan diantara keduanya. Dengan demikian diperoleh cukup bukti bahwa hipotesis $\mathrm{H}_{2}$ yang menyatakan citra Pulau Lombok sebagai destinasi wisata halal memiliki pengaruh positif terhadap loyalitaswisatawan yang berkunjung ke Pulau Lombok dapat diterima.

3. koefisien regresi yang dibakukan sebesar 0,652 pada hubungan kepuasan wisatawan terhadap loyalitas wisatawan dengan C.R. sebesar 2.800 dan $p_{\text {value }}=0,00$ (lebih kecil dari 0,05$)$ membuktikan adanya pengaruh positif dan signifikan diantara keduanya. Dengan demikian diperoleh cukup bukti bahwa hipotesis $\mathrm{H}_{3}$ yang menyatakan kepuasan wisatawan memiliki pengaruh positif terhadap loyalitaswisatawan yang berkunjung ke Pulau Lombokdapat diterima.

Wisatawanyang memiliki penilaian positif terhadap Pulau Lombok cenderung merasa puas untuk kunjungannya. Sebaliknya, wisatawan yang memiliki penilaian negative cenderung merasa kurang puas atau tidak senang.Temuan ini selaras dengan penelitian Sun, et al.(2013) yang melaporkan bahwa wisatawan dengan persepsi positif memperoleh kepuasan yang lebih baik pada pengalamannya.

Temuan penelitian ini mengindikasikan bahwasemakin puas wisatawan, mereka cenderung menunjukkan sikap loyalitas yang lebih tinggi terhadap destinasi wisata Pulau Lombok.Mereka, dimasa depan bermaksud mengunjungikembali, mengatakan hal-hal positif, dan merekomendasikan kepada oranglain.

Hasil penelitian ini mendukung pula temuan Coban (2012) yang membuktikan pengaruh positif citra destinasi terhadap kepuasan wisatawan. Selain itu, penelitian ini memperkuat penelitian Coban (2012) dalam hal indikator citra kognitif yang secara umum ada enam item berkaitan dengan pengeta-huan/keyakinan wisatawan mengenai destinasi wisata, terdiri dari atraksi wisata, fasilitas dasar, atraksi budaya, aksesibilitas dan substruktur pariwisata, lingkungan alam, danfaktor ekonomi.

Penelitian ini juga memperkaya temuan Artuğer et al. (2013) pada indikator citra afektif yang terdiri dari item kota yang hidup, kota yang bersemangat, dan kota yang menyenangkan. Hasil ini juga selaras dengan penelitian Mohamad et al. (2011) yang 
membuktikan bahwa citra berpengaruh positif terhadap kepuasan wisatawan. Penilaian yang berpengaruh besar terhadap kepuasan yaitu keindahan alam dan juga fasilitas yangbaik.

Citra Pulau Lombok sebagai destinasi wisata halal ditemukan berpengaruh signifikan terhadap loyalitas wisatawan dengan kontribusi sebesar 72\%. Halini menunjukkan bahwa wisatawan yang memiliki penilaian positif mengenai Pulau Lombok sebagai destinasi wisata halal menunjukkan sikap lebih loyal terhadap Pulau Lombok. Wisatawan yang sudah memiliki pengetahuan ataupun keyakinan mengenai citra kognitif (atraksi wisata, fasilitas dasar, atraksi budaya, aksesibilitas dan substruktur pariwisata, lingkungan alam, dan faktor ekonomi) dan citra afektif (Pulau yang bersih, higinis, dan menyenangkan) dapat menjadi loyal melalui perilaku tertentu. Perilaku wisatawan tersebut diantaranya bermaksud mengunjungi kembali di masa mendatang, mengatakan hal-hal positif, dan merekomendasikan Pulau Lombok kepada oranglain.

Temuan penelitian ini selaras dengan penelitian Artuğer et al. (2013) yang menyimpulkan bahwa terdapat pengaruh yang positif. Penelitian ini juga mendukung hasil penelitian Tasci danGartner (2007) yang menerangkan bahwa citra destinasi wisata bisa memengaruhi perilaku wisatawan yang diantaranya bermaksudmengunjungi kembali, ataupun merekomendasikan kepada orang lain. Selanjutnya, juga memperkuat penelitian Lobato et al. (2006); Chen dan Tsai (2007); dan Prayag (2008) yang mengkonfirmasikan bahwa perilaku dimasa depan yang menilai positif terhadap citra suatu destinasi pariwisata diantaranya adalah mengunjungi kembali dan merekomendasikan destinasi terkait kepada oranglain.

Bentuk perilaku nyata loyalitas wisatawan terhadap Pulau Lombok salah satunya terlihat dari kuantitas pengalaman kunjungannya. Mengacu pada gambaran karakteristik responden, tampak sebagian besar responden $(72,58 \%)$ telah melakukan kunjungan lebih dari lima kali ke Pulau Lombok. Hal ini menjadi petunjuk bahwa wisatawan merasa puas ketika mengunjungi Pulau Lombok dan cenderung melakukan kunjungan ulang.

Temuan penelitian ini mendukung penelitian Coban (2012) yang melaporkan bahwa kepuasan memiliki pengaruh positif terhadap perilaku setelah berkunjung, baik dengan melakukan kunjungan kembali ke destinasi wisata yang sudah dikunjungi dan atau merekomendasikannya ke orang lain. Hasil penelitian ini juga selaras dengan pendapat yang dikemukakan Lovelock et al. (2010), bahwa loyalitas sejati terhadap perusahaan (destinasi pariwisata) terdapat pada kepuasan pelanggan (wisatawan), dimana sangat puas atau menyenangi layanan yang diberikan. Bentuk loyalitas tersebut dapat berupa mengunjungi kembali destinasi pariwisata yang sama dan atau menyebarkan berita positif terkait destinasi pariwisata terkait.

Merujuk pada temuan penelitian, ditunjukkan bahwa kemampuan model penelitian yang dihipotesiskan untuk menjelaskan hubungan struktural yang ada diantara citra Pulau Lombok sebagai destinasi wisata halal, kepuasan wisatawan, dan loyalitas wisatawan memiliki nilai yang cukup besar yaitu 95,16\%. Nilai ini menggambarkan bahwa citra Pulau Lombok sebagai destinasi wisat halal memengaruhi loyalitas wisatawan melalui 
kepuasan yang dirasakan oleh wisatawan. Wisatawan yang memiliki penilaian positif terhadap Pulau Lombok kemudian pada saat melakukan kunjungan merasakan kepuasan dapat mengakibatkan mereka menjadi loyal terhadap destinasi wisata tersebut, yaitu dengan merekomendasikan ke orang lain, mengatakan hal-hal positif, dan atau melakukan kunjungan berulang. Hasil penelitian ini juga menunjukkan pengaruh yang kuat adalah pengaruh yang sifatnya tidak langsung diantara citra Pulau Lombok sebagai destinasi wisata halal terhadap loyalitas wisatawan melalui kepuasan wisatawan dengan angka persentase sebesar $42,8 \%$.

Pengaruh citra Pulau Lombok sebagai destinasi halal terhadaployalitas wisatawan melalui kepuasan wisatawan terjelaskan pula oleh deskripsi karakteristik responden.Data menunjukkan bahwa dari seluruhresponden, terdapat enam orang responden menunjukkan loyalitas yang tinggi terhadap Pulau Lombok dengan mengunjungi lebih dari 10 obyek wisata, dimana satu orang responden diantaranyatelahmengunjungi13obyekwisata. Jumlah pengalaman berkunjung tersebut didukung oleh pengetahuan mengenai Pulau Lombok itu sendiri, terutama pertimbangan keberagaman daya tarik wisatanya.

\section{Kesimpulan}

\section{KESIMPULAN DAN SARAN}

Secara keseluruhan, temuan penelitian ini menunjukkan bahwa: Citra Pulau Lombok sebagai destinasi wisata halal memengaruhi kepuasan wisatawan yang mengunjunginya, begitu pula citra Pulau Lombok sebagai destinasi wisata halal memengaruhi loyalitas wisatawan dalam bentuk merekomendasikannya kepada keluarga, teman, orang lain, serta berkeinginan untuk melakukan kunjungan berulang. Kepuasan wisatawan memengaruhi loyalitas mereka.

\section{Saran}

Beberapa saran yang diberikan adalah:

1. Sebagai destinasi wisata yang semakin popular, Pulau Lombok harus memiliki infrastruktur yang terus menerus ditingkat kuantitas maupun kualitasnya, layanan wisata yang berkualitas, sumber daya alam dan hiburan yang bervariasi yang harus disesuaikan dengan ekspektasi wisatawan. Untuk mendapatkan kesetiaan wisatawan terhadap destinasi wisata Pulau Lombok, maka wisatawan harus bisa merasa senang, rileks dan ceria selama kunjungan mereka.

2. Untuk mengelola unsur-unsur emosional ini, sarana-sarana tradisional untuk membangun infrastruktur, penyediaan layanan berkualitas dan tawaran hiburan yang beragam adalah masih belum cukup. Itu semua bisa dianggap sebagai persyaratan mutlak namun selain dari itu berbagai pelaku dalam sebuah tempat tujuan wisata juga harus melakukan koordinasi dan orientasi agar bisa menyesuaikan dengan kebutuhan wisatawan.

3. Stakeholders pariwisata Pulau Lombok masih perlu menganalisa bagaimana upaya agar bisa memastikan bahwa para wisatawan yang berkunjung ke Pulau Lombok 
mendapatkan citra afektif yang sangat positif. Karena hal iniakan membuat wisatawan mau mengulangi kunjungan mereka. Jika stakeholders pariwisata Pulau Lombok bisa menciptakan basis wisatawan yang setia dan mengulangi kunjungan mereka secara berkala, maka destinasi wisata Pulau Lombok akan mampu memberikan kontribusi nyata bagi perekonomian daerah Nusa Tenggara Barat umumnya serta peluang-peluang ekonomi dan lapangan kerja bagi para komunitas yang ada di sekitarnya.

\section{DAFTAR PUSTAKA}

Artuğer, S., et.al, (2013), The effect of destination image on destination loyalty: application in Alanya, European Journal of Business and Management, 5 (13): 124136.

Baker, D. A. \& Crompton, D. L. (2000), Quality, satisfaction and behavioural intentions, Annals of Tourism Research, 27(3), pp. 785-804.

Beerli, P. A., Martın, J. D. \& Moreno, G. S. (2002), Los Agentes que Conforman la Imagen de los Destinos Turisticos.I Coloquio Predoctoral Europeo de Turismo y Ocio ESADE-IMHI

Bigne', E. \& Andreu, L. (2000), The chain of the marketing of the tourist product, in J. E. Bigne' \& D. Lo'pez (Eds)Territorial Planning and Tourist marketing, pp. 113-132 (Castellon de la Plana, Spain: Universitat Jaume I).

Bigne', E., Sa'nchez, I. \& Sanz, S. (2005), Relationships among residents'image, evaluation of the stay and post-purchase behavior, Journal of Vacation Marketing, 11(4), pp. 291-299.

Bigne', E., Sanchez, M. I. \& Sanchez, J. (2001), Tourism image, evaluation variables and after purchase behaviour: Inter-relationship, Tourism Management, 22, pp. 607-616.

Bowen, D. (2001), Antecedents of consumer satisfaction and dissatisfaction (CS/D) on long haul inclusive tours: To reality check on theoretical considerations, Tourism Management, 22(1), pp. 305-314.

Coban, Suzan (2012), The Effects of the Image of Destination on Tourist Satisfaction and Loyalty: The Case of Cappadocia, European Journal of Social Sciences, 29 (2), pp. 222-232

Dye, Renee., (2000), "The Buzz on Buzz" Harvard BusinessReview, 78 (6).

Ghozali, Imam. (2012), Aplikasi Analisis Multivariate dengan Program IBM SPSS 20. Semarang: Badan Penerbit - Universitas Diponegoro

Joreskog, K.G. and Sorbom, D. (1982), Recent Developments in Structural Equation Modeling.Journal of Marketing Research, 19, 404-416

Kotler, P., dan K. L. Keller. (2008), Manajemen Pemasaran. Edisi Tiga Belas. Diterjemahkan oleh Bob Sabran. Jakarta: Erlangga.

Lobato, L.H., et.al. (2006), "Tourism Destination Image, Satisfaction and Loyalty: A Study in Ixtapa-Zihuatanejo, Mexico", Tourism Geographies, 8(4), pp.343-358

Lovelock Christopher.etal., (2010) Pemasaran Jasa, Edisi 7, Jilid 2. Erlangga: Jakarta

Pitana, IG., danIK. S. Diarta. (2009), PengantarIlmu Pariwisata.Andi: Yogyakarta.

Prayag, G. (2008), "Image, Satisfaction and Loyalty-The Case of Cape Town", Anatolia: An International Journal of Tourism and Hospitality Research, 19, (2), pp. 205-224.

Silverman, George. (2001). TheSecrets of Word of Mouth Marketing. How Trigger Exponential Sales Through Runaway Word of Mouth. USA: American Library Association 
Sobel, M. E. (1982), Asymptotic confidence intervals for indirect effect in structural equation models. In S. Leinhardt (Ed.), Sociological Methodology 1982 (pp. 290312). Washington DC: American Sociological Association

Sun, X., etal. (2013), Developingdestinationloyalty: The case of Hainan Island. Annals of Tourism Research, 43:547-577.

Tasci, A.D.A., dan Gartner, W.C. (2007), Destination image and its functional relationships. Journal of Travel Research, volume 45, halaman 413-425.

Tjiptono, Fandy (2008), Strategi Pemasaran. Edisi 3. Yogyakarta: Andi Offset 